\title{
Demographic Dividends: Emerging Challenges and Policy Implications
}

\author{
edited by Roberta Pace and Roberto Ham-Chande \\ New York: Springer, 2016 \\ Demographic Transformation and Socio-economic Development Series 6 \\ ISBN 978-3-31932707-5 \\ Hardcover US\$99.99, 184 pp.
}

\section{Reviewed by Margot Almond \\ Unaffiliated researcher (ret.)}

The economic impacts of aging are currently an important subject of discussion and debate. Countries are increasingly experiencing the economic impacts of population aging, as a result of declining fertility and mortality rates. In addition, there can be certain socio-economic advantages to these demographic transitions, and these benefits are known as demographic dividends. Governments, and indeed citizens, are increasingly concerned with the demographic dividends to be gained, as well as the pitfalls to be avoided, in addressing population aging.

Studying the differences between various countries in these demographic transitions and demographic dividends can help inform the public policy debate, in order to ensure that government policies support the realization of demographic dividends.

This book is a collection of seven articles by various authors, all on the general theme of demographic transitions. It is the sixth book in a series published by Springer on demographic transformation. The editors' stated aim is to examine the diversity of demographic dividend paths taken by various countries. Each of the articles examines one or more countries or sub-national areas to determine the onset of the so-called "window of opportunity" created by the demographic transition, and the extent or length of that window. In order to fully take advantage of the demographic transition, governments must use the window of opportunity to put in place policy supports, such as investments in education and health care, that act as enablers in the achievement of demographic dividends when the window of opportunity opens.

The regions/groups studied are Mexico, Sub-Saharan Africa, Latin America, India, the Mediterranean countries, Italy, and Indigenous populations in Canada, Australia, and New Zealand. The addition of an article focusing on countries with the oldest age structures in the world, such as Japan and Germany, would have rounded out this collection nicely. With such a wide diversity of countries being studied, it is obvious that many of the regions under study completed their demographic transition long ago, while others are still on the cusp. This huge range means that the approaches taken by each chapter must differ significantly, and this diversity of approaches makes for somewhat choppy reading.

Three of the articles (those on Latin America, Mexico, and Italy) examine both the demographic dividends as well as the demographic transitions, including some attempts made at ac- 
tually measuring the socio-economic dividends. In contrast, the remaining four articles (those on Sub-Saharan Africa, India, the Mediterranean countries, and Indigenous groups) focus on the demographic transitions, and where they do address the matter of dividends, it is largely a discussion at a theoretical level. This is not surprising, since it is impossible to measure the actual economic impact of something that has not yet occurred.

Most of the articles use common concepts such as the Total Dependency Ratio or Total Fertility Rate, or even crude birth and death rates, to measure the demographic transition, and each uses a slightly different approach to determine the timing of the resulting "window of opportunity" created. In contrast, the methods used to measure demographic dividends are more uniform, with GDP per capita and household savings rates being the preferred measures.

The book includes several innovative studies, including the Latin American examination of the so-called gender dividend, which is the increase in GDP that arises from increased female labour force participation. The authors present compelling evidence that the gender dividend may in fact be more economically significant than the demographic dividend, at least in several Latin American countries.

The article on Italy delves into the unusually significant impact of migration on population structure and aging. By way of illustration, Italy lost over 7 million people to emigration during the 1946-76 period, ${ }^{1}$ which naturally had a huge impact on its population of only 50 million in $1960{ }^{2}$

Another approach used in this book is to look at the impact of sub-populations who live among a majority population, in this case the Indigenous populations of New Zealand, Australia, and Canada. This is labelled the collateral dividend, because this dividend may be realized long after the "main" window of opportunity has closed, due to the different age structure of the sub-population. The author, Natalie Jackson, is just beginning her work on this emerging concept, and it will be interesting to follow it in the future.

The article on Sub-Saharan Africa used population projections to predict the timing of various countries' windows of opportunity. The authors of this article undertook a sensitivity analysis to determine the impact of different population projection series on their analysis, thus providing some unique insights into the importance of dataset selection.

Given the book's title, it was a little disappointing that the book did not have more articles examining the actual demographic dividends realized, especially since so many countries around the world have completed their demographic transitions. The three articles which did attempt to measure demographic dividends were quite fascinating to read. For example, the article looking at household savings rates in Mexico found that the traditional theoretical model of an upside-down U shape to savings rates through the life cycle did not quite fit. Rather, the authors found that there was a small but definite uptick in savings shortly before retirement age, resulting in an M-shaped savings curve.

Of course, there is no guarantee that demographic dividends will in fact be realized by any given country, despite their demographically-driven windows of opportunity. Two articles examined this topic, looking at sub-national regions to see why some states/regions were more successful than others in accruing demographic dividends. In the case of Italy, the authors argue that a government development fund actually subverted the potential demographic dividend for the southern region, and actually deepened the north-south gap within Italy. ${ }^{3}$ Conversely, Anrudh Jain argues that in India, some states were more successful than others in obtaining their dividends precisely due to their governments' early actions to increase investment in education and health.

1. Chapter 7 on Italy, by Roberta Pace and Naida Mignolli, p. 157.

2. World Bank, https://data.worldbank.org/indicator/SP.POP.TOTL?locations=IT

3. Chapter on Italy, p. 172. 
These investments ensured that their populations were well-prepared to take advantage of the demographic transition. In the case of Mexico, the authors note that while current government policies are not coordinated and effective to profit from the demographic transition, the window will still be open for several more years. The ongoing nature of these transitions confirms that there are many more books to be written on this subject.

The introduction by the editors nicely summarizes the theoretical underpinnings of work to date in the area of demographic transitions. It was somewhat surprising, however, that the state of current literature on actual dividends was not even mentioned.

This book fits well into the theme of this series of books, which is demographic transformation. Given that the series covers various aspects of transformation and socio-economic development, perhaps a future book could focus on demographic dividends in particular.

This is an interesting collection of articles, covering a broad spectrum of demographic transitions around the world. With much earlier research (and media coverage) often focused on the "perils" of population aging, it is worthwhile to be able to read material that focuses on the more positive potential dividends. 